\title{
Exploring surgical treatment for myocardial infarction
}

\author{
B. B. Milstein ${ }^{1}$
}

The surgical treatment of certain complications of myocardial infarction is now accepted as routine. Resection of chronic left ventricular aneurysms can be carried out with a low operative mortality (Cooley, Hallman, and Henly, 1964; Favaloro et al., 1968). Repair of a perforated ventricular septum has given good results, but the mortality has been high in those patients who must be operated on within four weeks of the infarction (Davison et al., 1964; Barnard and Kennedy, 1965; Campion et al., 1968). The treatment of persistent heart failure due to severe mitral regurgitation from rupture or dysfunction of a papillary muscle is also well established (Morrow et al., 1968). Even biventricular aneurysms combined with an acquired ventricular septal defect have been treated successfully (Stinson, Becker, and Shumway, 1969). However, there is still a large number of victims of myocardial infarction who suffer from complications for which medical treatment has little to offer at the present time. These complications include cardiogenic shock and chronic congestive heart failure.

\section{Left ventricular asynergy}

Attention is now being directed to the problem of focal asynergy of the left ventricular myocardium. This condition is one of the causes of cardiogenic shock and pulmonary oedema in the acute stage of the infarct, and of chronic left ventricular failure later. Gorlin, Klein, and Sullivan (1967) classified cases of ventricular asynergy according to the cine-angiographic findings into akinesis (lack of wall motion), and dyskinesis, or paradoxical movement. They found that akinesis was twice as common as dyskinesis, and that one or other form of asynergy was present in 24 of 100 patients with coronary artery disease submitted to cine-ventriculography.

\footnotetext{
${ }^{1}$ Address : Addenbrooke's Hospital, Cambridge.
}

Pulmonary oedema unresponsive to medical treatment has been thought in the past to be due to 'muscle failure'. Cardiogenic shock is a term which probably encompasses a variety of different pathological conditions, but when it is associated with a low cardiac output, muscle failure is thought to be responsible at least in some cases. Similarly, chronic congestive cardiac failure and low output in patients with coronary artery disease is normally attributed to myocardial ischaemia and fibrosis, leading to a diffuse loss of ventricular contractility. In some of these patients, necropsy fails to confirm the expected severity of generalized muscle atrophy.

Recent studies of ventricular function in myocardial infarction have identified a group of patients in whom localized left ventricular dysfunction is responsible for the haemodynamic disturbance. With increasing experience, investigators have become bolder in applying these techniques to patients soon after an episode of infarction. Coronary arteriography has been carried out safely within Io to 2I days of an infarct (Miller and Mymin, 1968). More recently, Begg et al. (I969) carried out full investigations, including right and left heart catheterization, selective coronary arteriography, and ventriculography, within ro-24 hours of admission after an acute infarct in five patients. There were no serious arrhythmias, but on the other hand none of the patients was hypotensive though all had raised left ventricular end-diastolic pressures. One patient developed a right coronary artery occlusion six hours after coronary arteriography; it is not clear whether he was one of this group of five. The numbers are small, but it is difficult to believe that these investigations could be carried out on large numbers of patients with recent severe myocardial infarction without considerable risk. 


\section{Mechanical and haemodynamic effects of local asynergy}

The reason for the asynergy is not clear. Katz and Hecht (1969) have pointed out that myocardial lactic acid production is increased 50 times in the anoxic area, and have shown how displacement by hydrogen ions of calcium bound to troponin could be a responsible factor. It is possible that this high concentration of lactic acid, or some other toxic substance, could diffuse into adjacent normal, or only slightly anoxic, muscle outside the area of infarction and thus be responsible for asynergy of a much larger area of ventricular wall.

At any rate, the asynergic area appears to be responsible for the impairment of left ventricular function. The non-contractile part is stretched with ventricular systole, and this reduces the effectiveness of the functioning muscle and diminishes forward flow. The increase in size of the left ventricular cavity leads to an increase of the wall forces required to generate a given ventricular pressure. This in turn leads to inefficiency because of a diminished rate of fibre shortening. Myocardial oxygen consumption is increased as shown by the increased tension time index. Finally, the infarcted area appears to be a focus of electrical irritability (Beck, 1962), and its removal can lead to a stability of rhythm and easier ventricular defibrillation.

Studies of left ventricular function in experimental myocardial infarction (Heimbecker et al., 1967; Pairolero et al., 1970) have shown a measurable decrease which is related to the size of the infarct. Significant haemodynamic changes may be found even when there is no obvious aneurysm or paradoxical movement (Herman et al., 1967). It is likely that an asynergic area develops in all cases of myocardial infarction, but restoration of function probably occurs in the majority of cases in a relatively short time.

\section{Techniques of investigation}

Some newer techniques, such as ultrasonic echography (Kraunz and Kennedy, 1970), radarkymography (Kazamias et al., 1970), and electrical impedance cardiography (Krohn et al., 1969), may allow the recognition of asynergic areas with less disturbance of the patient, and perhaps more accuracy, but at present quantitative left ventriculography is essential so that the geometry of the end-systolic and end-diastolic areas can be observed and the volumes calculated. Advances in electronic data processing by 'brightening' the area of opacification enable this to be done with quite small quantities of contrast material (Tsakiris et al., 1969). Kay et al. (1970) have suggested that ventriculography should precede coronary arteriography in order to avoid a false impression of impaired left ventricular function. Moreover, because retrograde left ventriculography may give rise to frequent ventricular ectopic beats they suggest that the late phase of an angiocardiogram provides more reliable information, in spite of the lesser degree of contrast. They consider that the single-plane angiocardiogram (Greene et al., 1967; Sandler and Dodge, 1968) in the right anterior oblique position is adequate for quantitative assessment. It is difficult to believe that an area of asynergy can be identified and quantified, wherever it occurs, from a single-plane study. Herman et al. (1967) thought that biplane angiography was essential, and this seems more reasonable.

It has been suggested that patients with post-infarction akinesis can be recognized clinically by the presence of a third heart sound, an enlarged transverse cardiac diameter, and electrocardiographic evidence of left atrial hypertrophy (Harrison, Crawford, and Lau, 1969). These features might be a guide in selecting patients for angiography, but are hardly specific.

\section{Experimental excision of infarcts}

Several experimental studies have shown the beneficial effects of excision of an infarct produced by progressive ligation of coronary arteries. Gordon Murray, the lone pioneer in so many branches of cardiac surgery, made the earliest attempts at excision of experimental infarcts nearly a quarter of a century ago (Murray, 1947). He resected left ventricular infarcts in dogs, and showed that the cardiac output and blood pressure improved after the resection. Heimbecker et al. (1967) and Heimbecker, Lemire, and Chen (1968) showed that the asynergic area appeared early after the ligations. In calves, they found that ventricular fibrillation was much easier to abolish after excision of the infarct. Treatment by cardiac massage and 15 minutes of circulatory support allowed resuscitation in 14 per cent of the animals. A 45-minute bypass improved this figure to 23 per cent, but after infarct excision all the animals could be resuscitated. Survivors in the three groups were II, I8, and 4I per cent, respectively. These authors noted that after excision of the infarct, the left ventricular stroke work increased, and the left atrial pressure fell to normal. Glass et al. (1968) carried out experiments to compare excision of anterior and posterior wall infarcts in dogs. The survival rate after resection of anterior infarcts was 50 per cent but excision of posterior infarcts compromised the 
posterior papillary muscle, causing severe mitral regurgitation. Jude et al. (1968) also found improvement in left ventricular function after excising the infarct which followed ligation of the anterior descending artery in dogs. About 35 per cent of the left ventricle can be excised in dogs without serious decrease in the stroke volume (Stein and Cordell, 1969), but the amount which can be excised safely in man is not known.

\section{Clinical reports}

A number of reports has appeared recently on the treatment of patients by this technique. Heimbecker et al. (1968) resected asynergic areas of the left ventricle in four patients. Three of these had septal perforations in addition, and two had suffered cardiac arrest before their operations. Clinically, they presented with severe cardiogenic shock, intractable pulmonary oedema, and evidence of large shunts at ventricular level. There was no response to intravenous isoprenaline or vasopressor drugs. Two of these patients survived the operation, and one made a complete recovery. Schimert et al. (1970) reported on 21 patients who presented with intractable cardiac failure. They excised 25-30 per cent of the ventricular mass using cardiopulmonary bypass. In addition, seven patients had mitral valve replacement, and two had closure of a ruptured ventricular septum. There were three operative deaths, and four more within six months. All except two of the survivors were relieved of their heart failure. Another report concerns the treatment of three patients with intractable heart failure from ventricular asynergy (Harman et al., 1969). Orthopnoea, paroxysmal nocturnal dyspnoea, and fluid retention were abolished. Two of them died at eight and nine months, but without a recurrence of congestive heart failure. These patients were carefully studied before and after operation. They all showed haemodynamic improvement, including an increase in cardiac index and a fall in left ventricular enddiastolic pressure. These authors considered that anterior location of the infarct, occlusion of the anterior descending artery with patency of the other two, a large end-diastolic volume, and a low ejection fraction were all factors favouring operation.

An interesting group of six patients was reported by Najafi et al. (1970). They were all dying from cardiogenic shock. All had severe hypotension, oliguria, and intractable metabolic acidosis, and were semicomatose. Three had had cardiac arrests. They all had left ventricular aneurysms, which were resected, and three had infarcts resected in addition.
One patient died from myocardial insufficiency. The others were all alive at periods of three months to three years after operation. The hazard of induction of anaesthesia was obviated by preliminary veno-arterial bypass via the femoral vessels under local anaesthesia.

\section{Infarct excision and revascularization}

Since direct revascularization procedures have been introduced, it has been suggested that the prognosis in patients who require aneurysmectomy may be improved if a coronary artery graft is carried out at the same time (Johnson and Lepley, 1970). It is clear that the same argument applies to cases of ventricular asynergy, and this procedure might help to avoid the disappointment of deaths within weeks or months of operation. Kay et al. (1970) treated 3I patients with chronic ventricular asynergy, combining the operation on the left ventricle with internal mammary implantation. Eight out of 15 patients who had an excision of one-third to one-half of the left ventricle during a short period of cardiopulmonary bypass recovered. Because of the critical condition of these patients in the postoperative period, another group of Io patients was treated by exclusion of the inactive part of the ventricle. This was done by passing mattress sutures on a large needle through the ventricle from the posterior to the anterior wall, and tying them over strips of Teflon felt. No bypass was required. Three of the ro patients died.

Asynergic areas of the posterior wall of the left ventricle present a more difficult problem, because excision would compromise the origin of the posterior papillary muscle. Kay et al. (1970) solved this problem by plication or imbrication of the affected area. There were no deaths among the six patients who were treated in this way.

All the surviving patients were said to be improved, but there are no clinical details in this paper. The mean ejection fraction improved from 0.39 to 0.55 in five patients who were studied before and after operation.

Direct reversed saphenous vein grafts from the aorta to a distal coronary artery branch are practicable in the majority of patients requiring revascularization operations (Johnson and Lepley, 1970; Effler, Favoloro, and Groves, 1970). Any coronary artery branch of $2 \mathrm{~mm}$. or more in diameter can be used for an anastomosis, and there is an increasing tendency to use multiple grafts. Moreover, it is now realized that patent healthy distal branches can be found beyond most obstructions and lengths of atheromatous artery (Johnson 
and Lepley, 1970). Assuming that these anastomoses will have a long-term patency rate better than similar small-vessel anastomoses in the lower limb, it seems logical to combine operations for ventricular asynergy with saphenous vein grafts, when extensive obstruction of the arteries remote from the infarcted area has been shown. Another reason for considering this approach is the lack of improvement in left ventricular function after internal mammary implantation (Manchester and Gorlin, 1969). Moreover, these patients require an immediate improvement in their coronary circulation, whereas the benefit of internal mammary implantation is delayed for some months.

\section{Operative localization of asynergic areas}

One difficulty which has been encountered at operation in these cases has been the localization of the area of asynergy. The limits of a ventricular aneurysm are usually obvious from the external aspect of the heart, and clearly visible from within the cavity. Schimert et al. (1970) have advised ventriculotomy to delineate the asynergic area, but this should be avoided if possible because of the increased risk of a low output state in the post-operative period. Others have used intravenous fluorescein, with observation of the myocardium under ultraviolet light (Armellini, Mersheimer, and Burman, 1968). This shows the ischaemic area well, but if the epicardial fat is more than $2 \mathrm{~mm}$. thick no fluorescence can be seen in those areas. Moreover, the skin and conjunctivae are stained yellow for several days afterwards. Methylene blue injected into the root of the aorta has also been used, but abandoned because of a suspicion of toxicity (Zikria et al., 1967).

A promising new method of localization of the area of damaged myocardium has been introduced by Daniel et al. (1969). Subendocardial infarction is detected from epicardial potentials, and is recognized when unipolar $Q$ waves of $25 \mathrm{msec}$. or longer duration are found, and when there is evidence of delayed subepicardial activation in bipolar complexes. Kaiser et al. (1969) prefer the bipolar electrogram, because a unipolar $Q$ wave may be recorded from adjacent normal tissue, whereas the decrease in amplitude and increase in duration of the bipolar electrogram provides excellent demarcation.

\section{Conclusions}

It is to be hoped that these advances will stimulate increased interest in the detailed study of left ventricular function after myocardial infarction. In the past, attention has been concentrated on haemodynamic studies; these have yielded valuable information, but they can only provide information about the total function of the left ventricle. If we are to detect cases of localized ventricular dysfunction we must focus more attention on end-diastolic and end-systolic tracings from angiocardiograms. Further experience with the newer techniques described here may considerably simplify diagnosis.

The second lesson to be learnt from this review relates to the selection of patients with angina for myocardial revascularization procedures. The contraindications to these operations have included 'non-contracting myocardium', a high left ventricular end-diastolic pressure, gross cardiomegaly, right ventricular failure, low cardiac output, massive left ventricular aneurysms, and an infarct in the previous six months. Many would not be as confident as Johnson and Lepley (1970) in saying that these factors should now be disregarded, but it would certainly be reasonable to look for areas of focal asynergy in such patients with intractable angina who have been refused surgical treatment, and reconsider revascularization and the possible benefit of an operation on the ventricular wall.

Thirdly, we must consider the question of improving the prognosis of patients with large non-functioning areas of the left ventricle. Kay et al. (1970) found that half the patients who were refused revascularization operations on this account died suddenly in one year or less. The mortality in this group from surgical treatment is about 30 per cent. It is too early at present to say whether surgical treatment improves the prognosis, and this is the only criterion of benefit in these patients. Those patients with intractable heart failure have little to lose, and if localized ventricular asynergy can be shown it seems reasonable to assess the advantages, if any, of resection of the asynergic area.

Finally, we must consider whether surgical treatment can help the patient with an acute infarct who is suffering from cardiogenic shock or pulmonary oedema unresponsive to the usual medical treatment. The mortality of these conditions is still in the region of 60-80 per cent, in spite of the use of volume replacement, positive pressure ventilation, and hyperbaric oxygenation. Assisted circulation, of which the most popular technique at the moment seems to be diastolic augmentation by intra-aortic balloon pumping (Kantrowitz et al., 1970), is promising, especially for those patients who develop circulatory failure within 36 hours of the infarction. However, Kantrowitz observed that no patient who 
developed 'shock' more than 36 hours after the infarction survived, and seven out of these eight patients died of ventricular rupture. Since it seems unlikely that the form of circulatory assistance was responsible for the ventricular rupture, Kantrowitz suggests that the assistance enabled the patient to survive long enough to allow the natural evolution of the infarct. In this group at any rate one should consider emergency resection of the infarct after radiological investigation, once the patient's condition has been improved by the circulatory assistance. Further investigations will be necessary to determine the frequency of localized necrosis in these cases, where death is probably related to the large amount of myocardium involved. It will also be important to follow patients who survive cardiogenic shock with the aid of a circulatory assistance device, in order to discover the incidence of cardiac symptoms and of permanent focal ventricular asynergy which may require surgical treatment later. Certainly at present there is no reason to operate on patients of this group in the recovery period.

The road to surgical treatment for coronary artery disease is littered with the wrecks of operations whose supposed benefits lay largely in the enthusiasm of their originators. This uncritical attitude was fostered by the absence of any criteria other than subjective ones by which to measure improvement. We now have the means of making objective assessments of ventricular function as well as of the coronary circulation before and after operation. One hopes that they will be fully utilized, in conjunction with appropriate control series, in the assessment of these promising, but still unproven, procedures. Even more important is to limit the indications for these operations, which will throw additional strain on hardpressed intensive care units, to the most urgent cases. It would be a tragedy if every cardiac surgeon were urged to leap on to this new bandwagon in a series of ill-advised operations with a high mortality, when in a year or two the results of operation in a smaller number of carefully selected and investigated patients will permit an assessment of the value of surgical treatment.

\section{References}

Armellini, C., Mersheimer, W. L., and Burman, S. O. (1968). The use of fluorescein for determining the site for internal mammary artery implantation. fournal of Thoracic and Cardiovascular Surgery, 56, 643.

Barnard, P. M., and Kennedy, J. H. (1965). Postinfarction ventricular septal defect. Circulation, 32, 76.

Beck, C. S. (1962). Fatal heart attack. American fournal of Surgery, 103, I57.
Begg, F. R., Kooros, M. A., Magovern, G. J., Kent, E. M., Brent, L. B., and Cushing, W. B. (1969). The hemodynamics and coronary arteriography patterns during acute myocardial infarction. fournal of Thoracic and Cardiovascular Surgery, 58, 647.

Campion, B. C., Harrison, C. E., Jr., Giuliani, E. R., Ellis, F. H., Jr., and Schattenberg, T. T. (I968). Ventricular septal defect after myocardial infarction. (Abstr.) Annals of Internal Medicine, 68, I 152.

Cooley, D. A., Hallman, G. L., and Henly, W. S. (1964). Left ventricular aneurysm due to myocardial infarction. Archives of Surgery, 88, 114.

Daniel, T. M., Cox, J. L., Sabiston, D. C., and Boineau, J. P. (1969). Epicardial and intramural mapping of activation of the human heart. A technique for localising infarction and ischemia of the myocardium. (Abstr.) Circulation, 40, Suppl. 3, 66.

Davison, T., Degenshein, G. A., Yuceoglu, Y. Z., Reyes, A. L., Jr., Levowitz, B., Dresdale, D. T., and Kantrowitz, A. (1964). Repair of ventricular septal defect following myocardial infarction. Annals of Surgery, 160, 33.

Effler, D. B., Favaloro, R. G., and Groves, L. K. (1970). Coronary artery surgery utilizing saphenous vein graft techniques. Clinical experience with 224 operations. Fournal of Thoracic and Cardiovascular Surgery, 59, 147.

Favaloro, R. G., Effler, D. B., Groves, L. K., Westcott, R. N., Suarez, E., and Lozada, J. (I968). Ventricular aneurysm - clinical experience. Annals of Thoracic Surgery, 6, 227.

Glass, B. A., Carter, R. L., Albert, H. M., and Rosenberg, D. M. (1968). Excision of myocardial infarcts. Experimental and clinical studies. Archives of Surgery, 97, 940.

Gorlin, R., Klein, M. D., and Sullivan, J. M. (1967). Prospective correlative study of ventricular aneurysm. Mechanistic concept and clinical recognition. American fournal of Medicine, 42, 512.

Greene, D. G., Carlisle, R., Grant, C., and Bunnell, I. L. (1967). Estimation of left ventricular volume by one-plane cineangiography. Circulation, 35, 6r.

Harman, M. A., Baxley, W. A., Jones, W. B., Dodge, H. T., and Edwards, S. (1969). Surgical intervention in chronic postinfarction cardiac failure. Circulation, 39, Suppl. I, 91.

Harrison, E. C., Crawford, D. W., and Lau, F. Y. K. (1969). Clinical prediction of post-infarction akinesis. (Abstr.) Circulation, 40, Suppl. 3, 102.

Heimbecker, R. O., Chen, C., Hamilton, N., and Murray, D. W. G. (1967). Surgery for massive myocardial infarction. An experimental study of emergency infarctectomy. Surgery, 6r, $5 \mathrm{I}$.

—, Lemire, G., and Chen, C. (1968). Surgery for massive myocardial infarction. An experimental study of emergency infarctectomy with a preliminary report on the clinical application. Circulation, 37, Suppl. 2, 3.

Herman, M. V., Heinle, R. A., Klein, M. D., and Gorlin, R. (1967). Localised disorders in myocardial contraction. Asynergy and its role in congestive heart failure. New England fournal of Medicine, 277, 222.

Johnson, W. D., and Lepley, D., Jr. (1970). An aggressive surgical approach to coronary disease. fournal of Thoracic and Cardiovascular Surgery, 59, 128.

Jude, J. R., Mobin-Uddin, K., Martinez-Farinas, L. O., Lombardo, C. R., and Smith, P. E., Jr. (1968). Surgical treatment of experimental myocardial infarction. Fournal of the American Medical Association, 203, 45I.

Kaiser, G. A., Waldo, A. L., Harris, P. D., Bowman, F. O., Jr., Hoffman, B. F., and Malm, J. R. (1969). New method to delineate myocardial damage at surgery. Circulation, 39, Suppl. I, 83. 
Kantrowitz, A., Krakauer, J. S., Jaron, D., Freed, P. Butner, A., and Rosenbaum, A. (1970). Ventricular support by means of phase-shift balloon pumping: experimental and clinical experience. (Abstr.) American fournal of Cardiology, 25, 107.

Katz, A. M., and Hecht, H. H. (1969). The early 'pump' failure of the ischemic heart. American fournal of Medicine, 47, 497.

Kay, J. H., Dunne, E., Krohn, B. G., Tsuji, H. K., Redington, J. V., Mendez, A., Dykstra, P., and Magidson, O. (1970). Left ventricular excision, exclusion, or plication for akinetic areas of the heart. Fournal of Thoracic and Cardiovascular Surgery, 59, 139.

Kazamias, T. M., Gander, M. P., Ross, J., Jr., and Braunwald, E. (1970). The localisation of asynergistic areas of the left ventricular wall by radarkymography. (Abstr.) American fournal of Cardiology, 25, 108.

Kraunz, R. F., and Kennedy, J. W. (1970). Ultrasonic determination of left ventricular wall motion in normal man. American Heart fournal, 79, 36.

Krohn, B. G., Dunne, E. F., Magidson, O., and Kay, J. H. (1969). Diagnosis of akinetic myocardium by electrical impedance cardiograms. (Abstr.) Circulation, 40, Suppl. 3, 126.

Manchester, J. H., and Gorlin, R. (1969). Left ventricular performance after myocardial revascularisation with internal mammary artery implantation. (Abstr.) Circulation, 40, Suppl. 3, I 39.

Miller, A., and Mymin, D. (I968). Selective coronary arteriography following acute myocardial infarction. (Abstr.) Circulation, 38, Suppl. 6, 139.

Morrow, A. G., Cohen, L. S., Roberts, W. C., Braunwald, N. S., and Braunwald, E. (1968). Severe mitral regurgitation following acute myocardial infarction and ruptured papillary muscle. Circulation, 37, Suppl. 2, 124.
Murray, G. (1947). The pathophysiology of the cause of death from coronary thrombosis. Annals of Surgery, 126, 523 .

Najafi, H., Hunter, J. A., Dye, W. S., David, H., Ardekani, R. G., and Julian, O. C. (1970). Emergency left ventricular aneurysmectomy for the dying patient. (Abstr.) American fournal of Cardiology, 25, II9.

Pairolero, P. C., McCallister, B. D., Hallermann, F. J. and Ellis, F. H., Jr. (1970). Experimental production and hemodynamic effects of left ventricular akinesis. (Abstr.) American fournal of Cardiology, 25, 120.

Sandler, H., and Dodge, H. T. (I968). The use of single plane angiocardiograms for the calculation of left ventricular volume in man. American Heart Fournal, 75, 325.

Schimert, G., Lajos, T. Z., Bunnell, I. L., Greene, D. G., Falsetti, H. L., Gage, A. A., Dean, D. C., and Bernstein, M. (I970). Operation for cardiac complications following myocardial infarction. Surgery, 67, 129.

Stein, M., and Cordell, A. R. (1969). Arrhythmias and left ventricular efficiency following infarction and infarctectomy. Archives of Surgery, 99, 802.

Stinson, E. B., Becker, J., and Shumway, N. E. (1969). Successful repair of postinfarction ventricular septal defect and biventricular aneurysm. Fournal of Thoracic and Cardiovascular Surgery, 58, 20.

Tsakiris, A. G., Donald, D. E., Sturm, R. E., and Wood, E. H. (1969). Volume, ejection fraction, and internal dimensions of left ventricle determined by biplane videometry. Federation Proceedings, 28, I358.

Zikria, B. A., Jaretzki, A., III, Zikria, E. A., and Ferrer, J. M., Jr. (1967). A technique for the demonstration of ischemic areas of the heart at operation. Surgery, 6r, 608. 